\title{
La economía social y solidaria como alternativa económica. Bienes comunes y democracia
}

\author{
Social and caring economy as an economic alternative. \\ Common goods and democracy
}

JAIME ABAD MONTESINOS Y MERCEDES ABAD MONTESINOS

UNIVERSIDAD DE VALENCIA

Artículo recibido: 29 junio 2013

Solicitud de revisión: 09 julio 2013

Artículo aceptado: 18 septiembre 2013

Resumen

El presente artículo trata de enmarcar la economía social y solidaria en el seno del actual debate producto de la crisis económica vigente, haciendo especial hincapié en las cuestiones relacionadas con los bienes comunes y la gestión democrática. La crisis presente ha puesto de manifiesto la necesidad de proponer modelos socio-económicos alternativos que aúnen democracia, compromiso social y sostenibilidad del medio ambiente. La economía social y solidaria, sin ser un programa homogéneo, está contribuyendo a proponer respuestas a algunos de los problemas actuales en materia de desempleo e integración social, revalorizando en los procesos económicos, no sólo los intercambios mercantiles, sino también los intereses sociales y los recursos naturales.

Palabras clave: Economía social y solidaria, bienes comunes, democracia, alternativas.

\begin{abstract}
This article aims to enlighten the importance of solidary and social economy in the present discussion, whose importance has increased as a result of the current economic crisis, making a special emphasis on subjects such as commons goods and democratic management. The crisis has brought up the need for alternative socio-economical management models which must combine democracy, social commitment and environmental sustainability. Solidary and social economy, without being a homogeneous program, are proposing answers to some of the present problems related to unemployment and social integration, contributing to increase the value of economic processes, not only in commercial exchanges, but also the social interest and natural resources.
\end{abstract}

Keywords: Solidary and social economy, commons goods, democracy, alternatives. 
Tras nosotros no bay continuidad; tras nosotros no existe una magnífica y gloriosa genealogía en la que la ley y el poder se muestren en su fuerza y su brillo. Salimos de la sombra, no teníamos derechos ni gloria, y precisamente por eso tomamos la palabra y comenzamos a decir nuestra bistoria.

(Foucault, 2003: 66)

\section{INTRODUCCIÓN}

En su célebre trabajo de 1925, Ensayo sobre el don, denunciaba el sociólogo francés Marcel Mauss el prejuicio ideológico que se había adueñado del pensamiento occidental al hacer del hombre, esencialmente, un «animal económico» (Mauss, 2010: 238). El proceso de racionalización llevado a cabo en el campo de la técnica y la economía, característico de la moderna sociedad burguesa, aunque había traído consigo una mejor optimización de los recursos disponibles, así como un incremento de la productividad, nos habría hecho olvidar que nociones como interés, beneficio, etc., no tienen sino una aparición reciente. Subyace en la obra de Mauss una crítica a determinados análisis clásicos de la economía de mercado que, presuponiendo ese economicismo innato en el hombre, han descartado ciertos fenómenos sociales como objeto de estudio.

La conclusiones expuestas por Mauss tienen importantes implicaciones sobre la política contemporánea, ya que, como él mismo expone, «al estudiar esos lados oscuros de la vida social, se llegará a aclarar un poco el camino que deben seguir nuestras naciones, su moral, al mismo tiempo que su economía» (Mauss, 2010: 240). El Ensayo sobre el don revela, en primer lugar, que no todos los fenómenos sociales pueden ser explicables en términos de compra y venta; pero también, que una economía no mercantilista continúa perdurando en nuestras sociedades de forma subyacente. Ciertos comportamientos y valores morales, como la hospitalidad, la generosidad, la cooperación o el gasto público, remiten a costumbres mucho más antiguas y más originarias en el ser humano que los intereses mercantilistas. Tal y como sostiene Mauss (2010: 238): «no es en el cálculo de las necesidades individuales donde encontraremos el método de la mejor economía». Determinados elementos sociales están más allá de los intereses particulares, puesto que afectan al bien común, son aquellos que vinculan individuos, tribus y sociedades en una red de intercambios complejos que forman el núcleo de la vida social. 
Sin embargo, los últimos decenios del siglo xx, como ya anticiparon Debord (1992) o Baudrillard (1970), han visto una mercantilización completa de la vida social que, amenazando con borrar todo espacio público, ha terminado por reducir toda motivación humana a la mera consecución de objetivos personales, y cuyas últimas consecuencias han desembocado en la actual crisis sistémica que afecta especialmente a Occidente. Dada la situación presente es cada vez más inevitable buscar modelos de gestión alternativos que nos permitan articular la vida social de una forma más solidaria, más justa, y más responsable con el medio ambiente. Parece entonces inevitable volver sobre aquellos valores y costumbres que ya destacó a principios de siglo Mauss en su trabajo: apoyo mutuo, cooperación, solidaridad, vida en común, etc. La crisis actual ha propiciado el desarrollo de diversas formas de entender la economía que, anteponiendo el bien común al interés privado, han puesto pues el acento en cuestiones sociales y morales que parecían condenadas a permanecer en segundo plano. La experiencia de la crisis ha puesto igualmente de manifiesto el cada vez mayor compromiso de ciertos sectores de la sociedad actual por pensar los márgenes, para articular desde allí, lejos de los centros de poder, proyectos socio-económicos que aúnan, en muchos casos, participación social, justicia distributiva y compromiso ecológico. Empresas autogestionadas, cooperativas, organizaciones solidarias, centros sociales... son alternativas locales muy diferentes entre sí y que aún están lejos de ser una respuesta global al sistema actual. Son pues un fenómeno reducido, emergente, y todavía frágil; un fenómeno que lucha por encontrar su espacio y consolidarse, pero que, lejos de primar el beneficio económico a toda costa, ha puesto en juego otros objetivos, trazando al mismo tiempo un vínculo con experiencias populares más antiguas, para no hacernos olvidar que la historia del capitalismo es también la de las luchas de resistencia y de la crítica a sus valores y prácticas (Santos, 2012: 33).

Una de estas alternativas surgida en los últimos años es el tema de estas páginas: la economía social y solidaria que está abriéndose camino poco a poco en el mundo actual, pero cuyos planteamientos conectan con la vieja tradición de pensamiento socialista y cooperativista. Porque en el fondo, como ya concluía Mauss (2010: 247-248) en el Ensayo sobre el don:

\footnotetext{
No hay otra moral, ni otra economía, ni otras prácticas sociales que estas [...]. Los pueblos, las clases sociales, las familias, los individuos, podrán enriquecerse, pero sólo serán afortunados cuando sepan sentarse, como caballeros, alrededor de la riqueza común. Es inútil ir a buscar lejos cuál es el bien y la felicidad. Aquí está, en la paz obligatoria, en el trabajo equilibrado, en común y en solitario alternativamente, en la riqueza atesorada y luego redistribuida en el respeto mutuo y la generosidad reciproca que la educación enseña.
} 


\section{ECONOMÍA SOCIAL, ECONOMÍA SOLIDARIA}

Si nos dirigimos a La Charte de l'économie sociale elaborada en 1980 por la CNLAMCA (Comité National de Liaison des Activités Mutualistas Coopératives et Associatives), el cual tendrá un importante papel en el renacimiento actual de la economía social, podemos encontrar una definición precisa de qué entendemos por ella:

El conjunto de entidades no pertenecientes al sector público que, con funcionamiento y gestión democráticos e igualdad de derechos y deberes de los socios, practican un régimen especial de propiedad y distribución de las ganancias, empleando los excedentes del ejercicio para el crecimiento de la entidad y mejora de los servicios a la comunidad. ${ }^{1}$

La economía social, sin embargo, no es en absoluto un concepto nuevo, puesto que ya en el siglo xix aparecen en Europa diferentes planteamientos -cercanos a lo que hoy entendemos por economía social- de la mano de pensadores utópicos como Robert Owen o Pierre-Joseph Proudhon, quienes comparten una clara preocupación moral por reorganizar la sociedad de su tiempo, en creciente desestructuración a consecuencia del liberalismo económico. La economía social surge en Europa íntimamente ligada al desarrollo de la Revolución Industrial y a la consolidación de los principios liberales en materia económica, cuya consecuencia inevitable fue la emergencia de la cuestión social ante la creciente pauperización de la clase trabajadora. Fuertemente marcada por el cristianismo social y el asociacionismo obrero, para los fundadores de esta forma de entender la economía su centro residía en tratar de «reconciliar la economía y la moral» (Azam, 2003: 151). Durante esta primera época las propuestas de los autores se moverían pues en la línea de una reconciliación de dos espacios francamente distanciados, y su orientación será principalmente actuar sobre los vínculos sociales, creando redes de cooperación con el objetivo de moralizar las conductas individuales. Sin embargo, será Charles Guide a principios del siglo xxi el conformador de una economía social más amplia, basada en valores como la cooperación, la solidaridad o el servicio público, la cual elaboró profundamente en obras como La coopération contre le capitalisme (2013) o Les institutions du progrès social (2008).

Conociendo la economía social un período de desarrollo y de intensas transformaciones hasta la época de entreguerras, experimentará una franca decadencia tras la Segunda Guerra Mundial y la consolidación del estado-

1 Boletín Oficial del Estado, núm. 76 de 30 de marzo de 2011, Ley 5/2011, de 29 de Marzo, de Economía Social. 
providencia. El modelo fordista-keynesiano, desarrollado en dicha época, supondrá un enorme esfuerzo de reorganización social y económica, que hará posible el espectacular crecimiento en los países occidentales durante tres décadas. La reestructuración de la relación entre el mundo del capital y el mundo del trabajo llevada a cabo por el estado del bienestar, no en los términos propuestos por la economía social, sino gracias al aumento del poder adquisitivo de la clase trabajadora, supuso la pérdida de terreno de las propuestas de la economía social ante el desarrollo de la sociedad de consumo y la mecanización del proceso productivo. No obstante, los compromisos sociales asumidos por el estado en materia de sanidad, educación, negociaciones colectivas, infraestructuras, etc. trajeron consigo una importante mejora de las condiciones de vida de la población asalariada. Los desequilibrios socio-económicos producidos por el liberalismo económico, que durante el siglo xix buscaron ser minimizados por la acción social y colectiva, pasaron entonces a ser corregidos por la intervención del Estado.Ahora bien, será precisamente la crisis de este modelo socio-económico, acaecida en la década de los setenta, el punto de emergencia contemporáneo de una nueva economía social.

Un nuevo tipo de pobreza aparece a finales de los años setenta, la cual las políticas neoliberales ${ }^{2}$ llevadas a cabo durante las últimas décadas no han hecho más que acrecentar: la exclusión de una parte de la sociedad del mundo del trabajo. La pobreza en las últimas décadas del siglo xx deja pues de expresarse en términos de sobreexplotación laboral, como había sucedido a lo largo del siglo precedente, para hablar en términos de desempleo y de exclusión social: la exclusión de aquellos «que han caído -o les han tirado- por la borda del vehículo del progreso económico» (Bauman, 2005: 82), y cuyo único recurso, tras el desmantelamiento del estado social, viene de la mano de la solidaridad ajena. Es el conjunto de nuevas iniciativas sociales surgidas para combatir la exclusión: empresas de inserción laboral, colectivos de solidaridad, régies de quartiers, etc. el origen de una economía social de nuevo cuño que recibirá el nombre de:economía solidaria. Tomando en consideración, no sólo los procesos productivos sino también el reforzamiento de los vínculos sociales, la economía solidaria «ambiciona servir al interés general y no sólo al interés colectivo de sus miembros» (Draperi, 2011:25), marcando con ello una clara distancia con la economía

2 Tomamos como «neoliberal» la definición dada por Thomas Coutrot (2002: 22): «es fundamentalmente neoliberal toda política que acepta -y profundiza- la dominación de los mercados financieros liberalizados y tiende, en consecuencia, a adaptar los derechos sociales y económicos de la población a las exigencias de la rentabilidad del capital». 
social tradicional, al trascender toda posible deriva corporativista. Lejos de participar del productivismo económico, para la economía solidaria la reciprocidad adquirirá un rol central a la hora de articular las propuestas en el seno de la sociedad civil. Esto le ha permitido obtener un significativo apoyo de los poderes públicos, ${ }^{3}$ y ha delimitado su espacio propio como aquel existente entre el sector privado y el sector público; formando así una línea de hibridación entre ambos, un punto de equilibrio y de reapropiación «de las grandes cuestiones que la economía liberal hace desaparecer bajo la ley inmutable de la mano invisible del mercado» (Azam, 2003: 158). Pero, al mismo tiempo, la economía solidaria se ha visto reducida a los sectores no-productivos, ajenos a los intereses privados y a las intervenciones estatales. Como ha destacado Serge Latouche (2003: 149), la economía solidaria entonces no sería sino «la mala conciencia de la ética de los negocios», aquella que, sin ser un verdadero cuestionamiento del sistema capitalista, apela a valores como la solidaridad para minimizar los efectos negativos del liberalismo económico: una propuesta que habla pues en términos de ética, pero no en términos de justicia. Entendida así la economía solidaria queda reducida a mero instrumento interno al sistema, destinado únicamente a cubrir los vacíos entre el capital y el estado. Renunciaría, por tanto, a desarrollar un debate en torno a los valores y principios rectores de la economía contemporánea -consagrados tanto en la Constitución Española, como en la práctica totalidad de las constituciones europeas- que son hoy dinamitados por la lógica del mercado. ${ }^{4}$ Sin embargo, es preciso no olvidar, como ya destacó el sociólogo portugués Boaventura de Sousa Santos (2003: 275), que la economía no sólo está constituida «por el capital, el mercado y los factores de producción sino que también participan de ella trabajadores, personas y clases con unas necesidades básicas, unos intereses legítimos y, en definitiva, con unos derechos ciudadanos».

Una breve relectura de algunos de los artículos de la Constitución permite tomar conciencia de que ésta no reconoce una simple economía de

3 La creación en algunas países europeos, como es el caso de Francia o Bélgica, de un secretariado de Estado para la Economía Solidaria, o la integración en Brasil de la economía solidaria en los programas públicos para desarrollo local, son ejemplos significativos al respecto (Boulianneet al., 2003: 49).

4 Podemos encontrar estos valores en varias constituciones europeas, como por ejemplo en la Constitución de Baviera en el art. 151: «Toda actividad económica sirve el bien común»; o en la Constitución Italiana donde dice, en el art. 41: «Será libre la iniciativa económica privada. No podrá, sin embargo, desenvolverse en oposición al interés social o de tal modo que inflija un perjuicio a la seguridad, a la libertad y a la dignidad humana. La ley determinará los programas y controles oportunos para que la actividad económica pública y privada pueda encaminarse y coordinarse con fines sociales». 
mercado, sino una economía social de mercado, ${ }^{5}$ y ello implica una orientación hacia un modelo económico socialmente justo, donde, tal y como dicta el art. 128.1: «Toda la riqueza del país en sus distintas formas y sea cual fuere su titularidad está subordinada al interés general». ${ }^{6}$ Sin embargo, declaraciones como la de Mario Draghi, presidente del Banco Central Europeo, al Wall Street Journal, afirmando la inevitable desaparición del modelo social europeo y la imposible renuncia a las medidas de austeridad (Wall Street Journal, 2012), hacen cada vez más acuciante la reflexión sobre el modelo socio-económico en el que queremos vivir, y la necesidad de plantear alternativas al capitalismo financiero. Pero hacen especialmente urgente la necesidad de proponer una gestión alternativa de los bienes comunes, sometidos hoy a los intereses del mercado.

\section{REINVENTAR LA DEMOCRACIA}

A nuestro juicio, si la economía social y solidaria va ganando actualmente espacio en el debate contemporáneo es porque vivimos tiempos espectrales. La posición optimista conservadora, que defiende la democracia liberal como forma de gobierno culminante, deja tras de sí inevitables fisuras que hoy se revelan en toda su crudeza: aumento del desempleo, desregulación financiera, depredación ecológica, recortes salariales, violación de derechos, etc. En un seminario que tuvo lugar en Buenos Aires en 2005, caracterizaba Santos (2006: 77) a las democracias liberales como «democracias de baja intensidad»: el claro resultado del proceso continuo de desarticulación de la política y su sometimiento progresivo a los dictados de la economía. Son democracias de baja intensidad aquellas que han perdido la batalla frente al capital, donde el supuesto reparto equitativo de poder entre los ciudadanos esconde profundas desigualdades político-económicas. Esta situación resulta

5 En el caso de la Unión Europea también podemos encontrar un importante acervo legislativo relacionado con la economía social; concretamente el art. 2 del Tratado de Lisboa establece que la Unión: «obrará en pro del desarrollo sostenible de Europa basado en un crecimiento económico equilibrado y en la estabilidad de los precios, en una economía social de mercado altamente competitiva, tendente al pleno empleo y al progreso social, y en un nivel elevado de protección y mejora de la calidad del medio ambiente». A su vez, el Comité Económico y Social en su dictamen: $L a$ dimensión ética y social de las instituciones financieras europeas, propone que tanto las instituciones europeas como los Estados miembros deben apoyar, además de la capacidad competitiva del mercado, también su dimensión ética y social.

6 Conviene destacar que la Constitución española, sin renunciar al derecho a la propiedad privada y a la herencia - reconocidas en el art. 33, reconoce la planificación Estatal en materia de economía con el objetivo de «atender a las necesidades colectivas, equilibrar y armonizar el desarrollo regional y sectorial y estimular el crecimiento de la renta y de la riqueza y su más justa distribución» (art. 131.1). 
ser cada vez más, en palabras de Santos (2006: 76), «una forma de fascismo social: el fascismo contractual», que reduce la democracia a mero procedimiento electoral sin redistribución social, naturalizando hasta tal grado las desigualdades que la condena a la exclusión de ciertos sectores de la sociedad se convierte en elemento estructural. En un contexto histórico donde, a pesar de mantenerse las estructuras democráticas, los poderes públicos son incapaces de velar por las condiciones que garanticen a los ciudadanos los derechos recogidos en las constituciones de sus respectivos países, el contrato social está en crisis y es preciso articular nuevos espacios de participación. Comienzan entonces a perfilarse las líneas de tensión que se trazan en nuestro presente: «El problema pasa por comprender que la democracia es parte del problema, y tenemos que reinventarla si queremos que sea parte de la solución» (Santos, 2006: 77).

Sostenía Derrida (1993: 89) en su obra Spectres de Marx, que una de las características esenciales del discurso hegemónico actual es la fuerza de disolución que opera en los límites del espacio público y del espacio privado: nuestro presente ha desdibujado profundamente los bordes de ambos. La consecuencia de ello es, según Derrida (1993: 89), un inevitable «espaciamiento del espacio público» que ha borrado la esencia de éste, y cuyo desenlace último es una descomposición de la política. El primer problema con el que se encuentran pues las sociedades occidentales contemporáneas es la urgente necesidad de recuperar una reflexión sobre lo común, sobre el espacio común y sobre aquellos bienes que tienen allí su centro, que no son propiedades de nadie sino que son comunes a todos los miembros de una sociedad, a los que no se les puede poner precio puesto que son el núcleo de la vida social, y escapan pues al mundo «totalmente monetarizado» (Kovel, 2009: 135) donde el capital tiene su dominio. Un pensamiento que busca desplazarse por los espacios de lo común, trazando las líneas de ruptura, desligando el valor monetario de las experiencias, los conocimientos y los derechos sociales, supone una apuesta por otra economía, una apertura hacia una economía social y solidaria no instalada únicamente en el beneficio monetario: una economía de la cohesión social y no de la fragmentación. Marcada por una clara voluntad político-social, dicha reflexión está llamada a recuperar con ello ese pliegue de realidad condenado a la ausencia.

Como ya destacó el filósofo André Gorz (2007: 95), un sistema económico basado en la producción ilimitada de mercancías no puede perpetuarse indefinidamente. Asimismo, ciertas competencias, experiencias o dimensiones del saber que «tienen vocación de ser universalmente accesibles y 
compartidas $[\ldots]$ son más útiles y enriquecedoras para todos porque responden al principio de puesta en común continua» (Gorz, 2007: 101). Es todo este "capital social», asimilado e interiorizado por el individuo, y puesto en marcha gracias a sus facultades lo que constituye el "capital humano» (Gorz, 2001: 63), que permite al individuo llevar a cabo un trabajo sobre sí mismo, desarrollarse, crecer, aprender, vivir. La economía social y solidaria propone pues recuperar ese capital social mencionado por Gorz, al poner de manifiesto la imposibilidad de disociar a ésta del marco donde se desarrolla, de los elementos no económicos con los que se entrelaza: factores sociales, culturales, morales, políticos o medioambientales. Porque la práctica totalidad de las iniciativas surgidas dentro de este modelo económico, a pesar de las enormes diferencias existentes entre ellas, se sustentan sobre una misma base: «velar y contribuir a que el acto económico sea el instrumento de la realización y el desarrollo de los hombres y de las comunidades y no el acto de su sometimiento» (Dembinski, 2004: 98). La propuesta pasa pues por una reconstrucción democrática de la economía, y ello implica necesariamente una reconstrucción democrática de la política.

\section{EL DEBATE SOBRE LOS COMUNES}

La concesión del premio Nobel de Economía en 2009 a Elinor Ostrom, por sus trabajos sobre los bienes comunes, muestra el creciente interés institucional por desarrollar un marco de gestión político-económica respecto de aquellos recursos que deberían mantenerse alejados de la lógica del mercado. La economía capitalista, movida por el interés de aumentar la tasa de beneficios, ha convertido los recursos básicos para la vida en mercancías, sometidas actualmente a la deriva especulativa de los mercados. Enfrentándonos actualmente a una crisis de modelo, tanto en lo socioeconómico como en lo ecológico, el enorme reto del presente pasa pues por encontrar los medios de gestión de los llamados bienes comunes, de forma medioambientalmente sostenible y socialmente justa.

Ha destacado Jean-Marie Harribey (2010:36) que la noción de bien común se desarrolla a raíz de la toma de conciencia de la necesidad de preservar determinados bienes que son "patrimonio común de la humanidad». Entrarían dentro de esta categoría, tanto bienes materiales, como es el caso de los recursos naturales -aire, agua, materias primas...-, como bienes in- 
materiales, es decir: conocimiento, sanidad, paz, estabilidad financiera... Ahora bien, la economía capitalista se asienta sobre la tentativa de extraer toda la actividad económica posible del espacio geográfico, legitimando así la explotación de la naturaleza en función de los intereses económicos, y justificando también, en segundo lugar, la explotación de las colectividades. Entrelazándose ambas íntimamente, la explotación del hombre se convierte así en una dimensión ligada a la explotación de la naturaleza, al depredar recursos naturales al mismo tiempo que mantiene a poblaciones enteras en la pobreza. Porque, como ya destacaba Marx en un conocido fragmento del Libro I de El Capital:

\begin{abstract}
Al igual que en la industria urbana, la fuerza productiva acrecentada y la mayor movilización del trabajo en la agricultura moderna, se obtienen devastando y extenuando la fuerza de trabajo misma.Y todo progreso de la agricultura capitalista no es sólo un progreso en el arte de esquilmar al obrero, sino a la vez en el arte de esquilmar el suelo; todo avance en el acrecentamiento de la fertilidad de éste durante un lapso dado, un avance en el agotamiento de las fuentes duraderas de esa fertilidad [...]. La producción capitalista, por consiguiente, no desarrolla la técnica y la combinación del proceso social de producción sino socavando, al mismo tiempo, los dos manantiales de toda riqueza: la tierra y el trabajador. (Marx, 1975: 612-613)
\end{abstract}

No obstante, el siglo xx nos ha mostrado que la colectivización forzada de los medios de producción llevada a cabo por los países de la órbita soviética ha dejado resultados aún más catastróficos para la población y el medio ambiente. Como muy acertadamente ha remarcado Michel Löwy (2006: 57): «un cambio de las formas de producción que no está acompañado de una gestión democrática y de una reorganización del sistema productivo sólo puede conducir a un callejón sin salida».

Los trabajos de Ostrom $(2000,2002)$ han puesto de manifiesto la imposibilidad de generalizar la teoría convencional de los recursos de acervo común -common-pool resources-, la cual concibe a los usuarios de dichos recursos como individuos que actúan de forma aislada, sin coordinar sus actividades y maximizando sus beneficios a corto plazo. La teoría convencional se asienta sobre una visión reductivista de la actividad humana,

7 Conviene tener presentes las diferencias existentes a la hora de delimitar los «bienes comunes»: Mientras que Elinor Ostrom (2012: 24) engloba bajo dicha etiqueta los recursos naturales comunes: regiones de pesca, explotaciones forestales, depósitos de agua, etc., cuya gestión no pude desvincularse de la deliberación colectiva; autores como Jean-François Draperi (2011:237), redactor-jefe de la Revue internationale de l'economie sociale(Recma), hablan de «bienes comunes en sentido amplio», incluyendo la educación, la paz, los medios de comunicación, etc., elementos que contribuyen a consolidar los lazos sociales y que se incluirían, según el esquema propuesto por Ostrom, dentro de la categoría de bienes públicos. 
al considerar al hombre incapaz de tomar conciencia de las consecuencias negativas de sus acciones a largo plazo y de articular formas de cooperación para minimizar dichas consecuencias, según destacaba Garret Hardin en su conocido artículo The Tragedy of the commons(1968). Sin embargo, la realidad dista mucho de reducirse al ejemplo de Hardin, tal y como expone Ostrom (2002: 3): «La rica literatura de estudios de caso ilustra una amplia diversidad de situaciones en que los usuarios que dependen de recursos de acervo común se han organizado para obtener mayores resultados de los que la teoría convencional predice». Es para Ostrom la autoorganización un bien público en sí mismo, capaz de generar reglas de uso, derechos y deberes para los usuarios, que ven fortalecidas la cohesión con las actividades de monitoreo y participación, así como de sanción en el caso de transgresión de las normas colectivamente aceptadas.

Subyace a esta propuesta una diferente concepción de la interacción social, no como suma de voluntades particulares, sino como proyecto colectivo estrechamente ligado a los recursos compartidos. La alternativa a una concepción de la naturaleza como fuente explotable de recursos se desarrolla actualmente a partir de la concepción que considera los recursos naturales como bienes comunes (Draperi, 2011:236), transciendo así la dicotomía tradicional entre bienes privados y bienes públicos, entre gestión privada y gestión estatal. La principal aportación pues de la economía de los comunes, en este sentido, es poner el acento sobre la gestión colectiva y democrática de los mismos. ${ }^{8}$

Destacaba Polanyi, en su conocida obra La Gran Transformación, que la organización productiva y distributiva en las sociedades primitivas no se llevaba a cabo por motivaciones lucrativas, ni por ninguna instancia movida exclusivamente por intereses económicos, sino por dos principios aparentemente alejados del campo económico: la «reciprocidad» y la «redistribución» (Polanyi, 1989: 90). La necesidad de gestionar los recursos naturales, esenciales para el mantenimiento de las comunidades, y por tanto no reductibles a cuestiones de rentabilidad económica privada, pone de manifiesto la radical actualidad de las tesis de Polanyi en su crítica al liberalismo económico. La gestión de los recursos naturales no puede sino sustentarse sobre la toma de conciencia de las interacciones sociales y

8 Sin embargo, no podemos obviar que la auto-organización en materia de gestión de recursos en absoluto es, en palabras de la propia Ostrom (2000: 47), «una panacea»; ciertas situaciones ponen de manifiesto sus debilidades: la sobrexplotación o subexplotación como consecuencia de errores de cálculo, los posibles fallos de monitoreo o supervisión, etc. En definitiva, la autogestión y la autoorganización se van afectadas por las mismas dificultades a las que se enfrentan la planificación estatal o la gestión privada. 
medioambientales que en ellos se inscriben. Tal gestión exige pues una autoorganización y una autogestión que, primando el interés general por encima del lucro privado, teja una red de intercambios sostenible y equitativa, permitiendo a todos los miembros de la comunidad, como ya escribió Marcel Mauss (2010: 248), «sentarse, como caballeros, alrededor de la riqueza común».

Esta concepción alternativa de la gestión de los recursos remite necesariamente a la acción colectiva, a la praxis social y política que traza un camino distanciándose de las empresas privadas y del Estado, y mantiene estrechos lazos con algunas propuestas de la economía social y solidaria. Los casos propuestos por Ostrom en su obra El gobierno de los comunes. La evolución de las instituciones de acción colectiva, ponen de manifiesto que el Estado y el mercado son incapaces de lograr un uso productivo de los recursos naturales dilatado en el tiempo (Ostrom, 2000: 26). El capitalismo considera los recursos naturales como una fuente de riqueza dada al ser humano y legítimamente explotable, pero no tiene en cuenta que el espacio geográfico, allí de donde extrae lo recursos, «es una dimensión de la vida social» (Draperi, 2011: 222), el marco donde ella se desarrolla.

Parece por tanto necesario una territorialización democrática de la economía, que atienda las necesidades de las comunidades y gestione los recursos de forma sostenible: «una alternativa económica fundada sobre el intercambio recíproco que respete la multiplicidad de culturas» (Draperi, 2011: 178). Concebidos como bienes comunes, los recursos naturales se estructuran como construcciones colectivas establecidas mediante acuerdos, más que como meros recursos sometidos a la lógica del beneficio. Son pues relaciones sociales regidas por la norma de la reciprocidad y articuladas necesariamente de forma democrática en el respeto mutuo. ${ }^{9}$

Según ha puesto de manifiesto la ocDE (2008) el crecimiento económico de las últimas décadas ha traído consigo el aumento de las desigualdades, tanto de las rentas de trabajo como de las rentas de capital, situación especialmente agravada a mediados de los años noventa con la progresiva reducción de políticas públicas de redistribución social. No obstante, a estas desigualdades se añaden a escala global, «las desigualdades medioambientales y las desigualdades de acceso a los bienes comunes» (Azam et al., 2007: 62). Los proyectos de economía social y solidaria representan, en la

9 Ahora bien, los sistemas de reciprocidad no son ajenos a determinadas dificultades, como bien ha destacado Éric Sabourin (2007: 212): el paternalismo, el patronazgo, el clientelismo o las venganzas personales. Es necesaria pues la existencia de determinadas instituciones que regulen las dinámicas de reciprocidad, evitando que se vean distorsionadas, por situaciones como las mencionadas. 
mayoría de los casos, una apuesta alternativa por la gestión de los recursos naturales de forma sostenible, así como una revalorización de los elementos no mercantiles implicados en el proceso productivo. Su funcionamiento inspirado en principios democráticos, junto con su apuesta por mantener unos valores sociales relegados a un segundo plano por la tónica imperante, se articulan sobre un ideal de mayor justicia social, privilegiando el capital social por encima del capital financiero. Porque, como ha remarcado Santos (2012: 41), buscan «la creación de formas de sociabilidad solidarias basadas en el trabajo colaborativo y en la participación democrática para la toma de decisiones sobre las empresas».

Esto puede verse en casos como el de las cofradías de pescadores, las cuales son corporaciones de derecho público, sin ánimo de lucro, cuyo objetivo es representar los intereses económicos de todos aquellos relacionados con la actividad pesquera. Ahora bien, su actividad, al mismo tiempo que busca satisfacer los intereses de sus socios, contribuye al desarrollo local, fomentando la cohesión entre las diferentes comunidades, para actuar conjuntamente en busca de un beneficio común, garantizando igualmente la sostenibilidad del medioambiente a largo plazo, del que depende su modo de vida. ${ }^{10}$ Un caso diferente a tener en cuenta sería el de la granja La Fageda, un claro ejemplo donde se entrelazan la economía social y la solidaria. Esta cooperativa, establecida en Girona y dedicada a la fabricación de productos lácteos, además de reciclar sus propios residuos y alimentar a los animales con piensos naturales, ofrece, a su vez, empleo a personas con discapacidad o trastornos mentales. Realiza pues una actividad económica siguiendo un funcionamiento democrático medioambientalmente sostenible; pero, por otro lado, realiza una función social ofreciendo trabajo a personas discapacitadas, las cuales dedican parte de su jornada diaria a realizar actividades destinadas favorecer el desarrollo de sus habilidades y de su integración (La Fageda, 2010).

El desplazamiento de los centros de poder asentados en estructuras jerárquicas, propias de las sociedades de capital, hacia estructuras horizontales, supone una descentralización organizativa y un compromiso con la inclusión de todas las personas implicadas en el proceso productivo, apostando por la participación directa de estas en la toma de decisiones y en el desarrollo de nuevas propuestas, así como una redistribución más equi-

10 Conviene destacar que en algunas ocasiones las cooperativas y las cofradías de pescadores también contribuyen a la creación de redes solidarias como es el caso de la Cofradía de Pescadores de San Pedro de Vinaròs, la cual ha colaborado en un programa de reparto gratuito de pescado entre diversas asociaciones benéficas. (Cfr. http://www.levante-emv.com/castello/2012/09/24/solidaridad-crisiscastello/938445.html). 
tativa de las riquezas. Ello trae consigo necesariamente una articulación más dinámica y cohesionada, al crear nuevos espacios de comunicación interpersonal, así como «una nueva conceptualización del poder» (Aguirre y Altuna, 2009: 74), ${ }^{11}$ orientado al interés colectivo y a la interacción social. Ahora bien, la economía social y solidaria no es un proyecto institucional predeterminado, sino una alternativa compartida, «un conjunto de principios de vida en sociedad» (Dembinski, 2004: 104) que remiten a dos esferas de necesidades inseparables para toda persona: las necesidades materiales y las necesidades relacionales.

El individualismo capitalista, que dinamita los vínculos sociales, ha convertido el mundo en mercancía y ha reducido todo intercambio a intercambio comercial, haciéndonos olvidar «que la libertad individual solo puede ser producto del trabajo colectivo» (Bauman, 2001: 15). Tanto los recursos naturales como los bienes socio-culturales no son mercancías, sino el espacio sobre el que se desarrolla la vida social, son pues «nuestro biotopo» (Flahault, 2005: 379). Son la red que estructura y cohesiona la sociedad, y sólo en sociedad se puede articular un debate sobre ellos. La apuesta entonces es reinventar lo colectivo; porque, como ha remarcado Zygmunt Bauman (2001: 16): "no llegaremos muy lejos sin hacer que regresen del exilio ideas como el bien público, la sociedad buena, la equidad, la justicia, esas ideas que no tienen sentido si no se las cultiva colectivamente».

\section{CAMINOS ALTERNATIVOS}

En el panorama de sombras actual queda, no obstante, espacio para las alternativas; como ya señaló Santos (2012: 15), «esta crisis tiene otro contexto y es que la gente, de alguna manera, está resistiendo en todas partes». Recientemente en la ciudad de Tesalónica -Grecia-, la empresa Vio.Me, dedicada a la fabricación de materiales de construcción y abandonada por sus propietarios, ha sido ocupada por los trabajadores, quienes organizados de forma asamblearia y sin ninguna afiliación política, decidieron ocupar la fábrica y ponerla bajo control obrero con el objetivo de reactivar la producción (VioMe, 2013). Theodoros Karyotis, portavoz de la Iniciativa de Solidaridad con Vio.Me, ha destacado como referente el Movimiento de

11 No obstante, si bien esto es cierto para las pequeñas cooperativas, como muy acertadamente ha mostrado Yan de Kerorguen (2009a) en su artículo: L'économie sociale, une réponse au capitalisme financier?, en ocasiones los límites entre una gran cooperativa, como es el caso de la cooperativa Mondragón, y una multinacional son borrosos. 
Empresas Recuperadas, surgido en Argentina tras la crisis de 2001, exponiendo igualmente el deseo de seguir adelante con el proyecto de Vio.Me y fundar una cooperativa de trabajadores (Palma, 2013).

Por otra parte, aquí en España, concretamente en Cataluña, surgió hace tres años la Cooperativa Integral Catalana (CIC). Organizada de forma asamblearia y autogestionada, esta cooperativa ha sacado adelante una serie de proyectos colectivos en materia de educación, alimentación y sanidad, llegando incluso a crear su propia moneda como medio de intercambio. ${ }^{12}$ Entre los principios generales que sustentan este proyecto destacan: la cooperación y la solidaridad entre sus miembros, la democracia directa, la equidad, el rechazo de la acumulación monetaria como objetivo, así como el acento puesto en la atención a las necesidades básicas, entre otros muchos (CIC, 2013). Estos son sólo algunos ejemplos surgidos en Europa a raíz de la crisis, pero que, como vemos, se entrelazan con experiencias de países de fuera del viejo continente.

Sin duda es cierto que "vivimos en tiempos de preguntas fuertes y de respuestas débiles» (Santos, 2010: 7), y son ellas aún respuestas que no suponen un cambio global de paradigma. Pero cada vez es más evidente que la respuesta dominante es una no-respuesta, pues deja en segundo lugar las necesidades más básicas de las personas en aras del beneficio y la rentabilidad. Las cooperativas de trabajadores y otras empresas del llamado tercer sector se han revelado como un modelo de gestión más equitativo y democrático a la hora de redistribuir la riqueza y el poder, consiguiendo satisfacer las necesidades de sus miembros y reducir las desigualdades económicas, sin olvidar en muchos casos el compromiso medioambiental. ${ }^{13}$

Lejos de ser la renovación de la economía social y solidaria una mera recuperación de fórmulas decimonónicas, que vuelven a nosotros ante la crisis del Estado del bienestar, es un fenómeno que se encuentra «adaptado a una sociedad en constante proceso evolutivo, creador y generador de

12 Como ha expuesto en un artículo Xavier Ricard (2011: 108), director de cooperación internacional en el Comité catbolique contre la faim et pour le développement (CCFD-Terre Solidaire), las monedas locales están conociendo actualmente un verdadero desarrollo como «sistema de intercambio paralelo, destinado a animar el consumo de productos locales y la redistribución monetaria en favor de proyectos de interés colectivo", contribuyendo de esta forma a lograr una cierta autonomía de los pequeños productores-consumidores respecto del gran capital.

13 Consciente de esta realidad, la onu declaraba el 2012 Año Internacional de las Cooperativas, con el objetivo de contribuir a su promoción, así como a la concienciación sobre su importante contribución al desarrollo de las colectividades, tanto económico como social. Por ello mismo, tal y como se recoge en la Resolución 64/136. Las cooperativas en el desarrollo social, se instaba a los gobiernos a revisar las disposiciones jurídicas precisas para favorecer su desarrollo, estableciendo las condiciones necesarias para que las cooperativas se encuentren en pie de igual respecto de otras empresas comerciales. 
formas empresariales nuevas» (Jeantet, 1999: 16). Cierto es que el primer problema que encuentra el tercer sector a la hora de desarrollar una definición precisa de sí es su gran diversidad interna; además, la complementariedad entre la economía social y la economía solidaria es todavía una labor por realizar (Laville, 2001: 39). Es preciso ser conscientes, como ha destacado Draperi (2011: 3), de que no existe un verdadero proyecto homogéneo de economía social y solidaria a escala global, sino una red de propuestas dispares, en ocasiones de difícil relación. Esta dificultad de equiparación es evidente entre las cooperativas, que buscan satisfacer las necesidades de sus miembros de forma equitativa, pero deben competir en una sociedad de mercado, y las empresas dedicadas al voluntariado y a la integración social. No obstante, es en la acentuación de proyectos concretos donde se pueden trazar las líneas para llegar a una estrategia común, marcada por una gestión democrática de los bienes comunes y una revalorización del capital social, que ponga en tela de juicio el reduccionismo económico operado por la sociedad de mercado. Dicha estrategia es pues una apuesta socio-política, que busca «una democratización de la economía, al articular las dimensiones de reciprocidad y de redistribución de la solidaridad para reforzar la capacidad de resistencia de la sociedad a la atomización social» (Laville, 2001: 47-48).

Con el agravamiento de la crisis en algunos países europeos, está dándose un desarrollo de empresas del tercer sector en espacios que antes eran competencia del sector público, esto es especialmente relevante en ámbitos como los servicios sociales o la inserción laboral. La economía social y solidaria está contribuyendo a crear una verdadera red asistencial en una época como la actual, donde el desempleo afecta a miles de familias en Europa, y aumenta sin cesar el número de personas en riesgo de exclusión. No obstante, esta focalización de la economía social y solidaria ha sido criticada por figuras como Nancy Neamtam o Thierry Jeantet. ${ }^{14}$ El sistema capitalista margina la economía social y solidaria y la utiliza equivocadamente al aprovecharla para atender sus vacíos, cada vez más acusados; puesto que la función de dicha economía no es reequilibrar la cohesión social, fracturada por la economía de mercado, sino contribuir a desarrollar una nueva visión de la sociedad, más democrática, más justa: «su verdadera libertad -en palabras de Jeantet- es ser un verdadero proyecto político» (De Kerorguen, 2009b). En términos similares se expresa Neamtam (2003: 129) al

14 Nancy Neamtam es Presidenta-directora general del Chantier de l'economiesociale. Thierry Jeantet es Director general de EUREsA y Presidente de Les Rencontres du Mont-Blanc, y uno de los mayores expertos europeos en el tema. 
señalar que, si bien la economía solidaria está jugando actualmente un rol esencial allí donde el estado está ausente, su destino es otro: «una radicalización democrática a nivel local, regional e internacional»; es pues una apuesta política por una renovación democrática a todos los niveles.

El espacio público queda por tanto como el lugar a recuperar, como centro del debate desde el que reconstruir las alternativas. Las iniciativas de economía social y solidaria están dando resultados a pequeña escala, sin embargo, conviene ser conscientes de los conflictos internos existentes, es decir, de la dificultad de articular una «convergencia de intereses» (Latouche, 2003: 147) entre los distintos actores de una economía que se pretende plural desde sus orígenes. Obviar esta realidad y confiar en la voluntaria aceptación de las reglas de juego democrático por todos los actores es caer en un "optimismo voluntarista» (Latouche, 2003: 147). Porque los valores hegemónicos que contribuyen a reforzar el sistema vigente van en la dirección opuesta a las prácticas sociales y solidarias. Además, como ha remarcado Santos (2003: 253), parece problemático que el «principio de comunidad» sobre el que se asienta la economía social y solidaria siga teniendo, después de décadas de descomposición, «la autonomía y la energía necesarias para liderar una nueva propuesta de regulación social, más justa y capaz de restablecer aquella ecuación entre regulación social y emancipación social». La apuesta pasa entonces por poner en juego otros valores distintos a los imperantes, y que nos llevan a los ya señalados en las primeras décadas del siglo xx por Marcel Mauss (2010: 248), el respeto mutuo y la generosidad reciproca que nos enseña la educación. La economía social y solidaria no puede, por tanto, dejar de lado la necesidad de una renovación profunda de la forma de entender la interacción entre los individuos, que tenga en cuenta una recuperación democrática de la gestión de los bienes comunes. Es preciso, pues, una teoría de la acción colectiva, que proponga alternativas de autoorganización y permita dar respuesta a los inevitables problemas a los que están expuestas (Ostrom, 2000: 56). Porque la economía social y solidaria no es la fuerza de empuje contra la sociedad de mercado, sino un tejido de propuestas alternativas, algunas muy diferentes entre sí, pero que comparten un núcleo común: la no identificación de mercado con mercantilismo. Todas ellas comparten la toma de conciencia de que existen otras prácticas humanas más valiosas: aquellas que articulan la vida en común y las interacciones sociales en el seno de una comunidad. Su proyecto pues:

No tiene un objetivo grandioso como el «derrocamiento del capitalismo» o su transformación radical, sino a una lenta modificación de los lugares comunes (de las represen- 
taciones comúnmente compartidas) que conciernen al ser humano y a la sociedad. Un cambio que, si se opera, mermará la fuerza del discurso dominante y volverá legitima otra manera de pensar y actuar. (Flauhaut, 2005: 382).

\section{CONCLUSIÓN}

Si estas páginas se han propuesto un objetivo es trazar un recorrido, necesariamente breve y fragmentario, a través de diversas experiencias imposibles de obviar actualmente, las cuales ponen de manifiesto otra forma de interacción social y de gestión de los recursos, constituyéndose como posible alternativa a las prácticas hoy dominantes en materia económica. Dichas prácticas son cada día más y más cuestionadas, ya que dejan en segundo lugar las cuestiones sociales más relevantes, al potenciar la competitividad individual frente a la cooperación y la solidaridad, primando así el beneficio privado por encima del interés colectivo. La economía social y solidaria supone pues un proyecto socio-económico, si bien no homogéneo, como se ha podido ver en este trabajo, pero que trae consigo un conjunto de propuestas que están haciendo frente a algunos de los problemas que afectan a las sociedades contemporáneas.

Nuestra intención con este artículo ha sido arrojar un poco de luz sobre una serie de experiencias, algunas recientes y otras que se remontan a décadas atrás, que moviéndose dentro del marco de la economía social y solidaria están dando resultados positivos, tanto en materia económica como social. No estando movidas únicamente por intereses mercantiles, su organización democrática hace hincapié en aspectos del sistema económico que van más allá del mero lucro, como son, entre otros, los derechos e intereses de los trabajadores y los bienes relacionales. Ahora bien, conviene tener presente que dicha alternativa económica no se ve exenta de dificultades a la hora de alcanzar acuerdos sobre la gestión de los recursos comunes. No obstante, al primar los intereses sociales y la sostenibilidad del medio ambiente, ella constituye un modelo económico socialmente más justo y democrático.

\section{BIBLIOGRAFÍA}

Aguirre Aramburu, A. y R. Altuna Erle (2009): «Retos y orientaciones para la innovación en las cooperativas de Mondragón ante la crisis», Projectics 
/ Proyéctica / Projectique, 3, pp. 65-77. [http://dx.doi.org/10.3917/ proj.003.0065].

AzAm, G. (2003): «Économie sociale, tiers secteur, économie solidaire, quelles frontières?», Revue du MAUSs, 21, pp. 151-161. [http://dx.doi.org/10.3917/ rdm.021.0151].

AzAM, G.y otros (2007): «Construire un monde écologique et solidaire», L'Économie politique, 34, pp. 60-71. [http://dx.doi.org/10.3917/leco.034.0060].

Baudrillard, J. (1970): La société du consommation, Paris, Denoël.

Bauman, Z. (2001): En busca de la política, Buenos Aires, FCE.

- (2005): Vidas desperdiciadas, Barcelona, Paidós.

Boulianne, M. y otros (2003): «L'espérance économie solidaire a principes économie solidaire et mondialisation», Revue du MaUss, 21, pp. 47-54. [http://dx.doi.org/10.3917/rdm.021.0047].

Boutillier, S. (2002): «Économie solidaire, repères et éléments d'une critique»,

Innovations, 15, pp. 9-19. [http://dx.doi.org/10.3917/inno.015.0009].

Cooperativa Integral Catalana (Cic) (2013): «Iniciativa en transició per a la transformació social de baix, mitjançant l'autogestió, l'autoorganització i el treball en xarxa», [en línea] [http://cooperativa.cat/que-es-la-cic-2/ principis-generals], consultado el 21 de junio de 2013.

Coutrot, TH. (2002): «Reconstruire l'imaginaire de la transformation sociale», Mouvements, 23, p. 22-28. [http://dx.doi.org/10.3917/mouv.023.0022].

De Kerorguen, Y. (2009a): «L'économie sociale, une réponse au capitalisme financier?», Le Monde diplomatique, julio [en línea]. Consultado el 5 de abril de 2013, [http://www.monde-diplomatique.fr/2009/07/DE_KERORGUEN/17594]. - (2009b): «L'économie sociale contre la crise économique: entretien avec Thierry Jeantet, directeur général d'Euresa»,Place publique. Le site des initiatives citoyennes, 6 de julio de 2009. [en línea]. Consultado el 5 de abril [http:// www.place-publique.fr/article/l-economie-sociale-contre-la-crise].

Debord, G. (1992): La société du spectacle. Paris, Gallimard.

Dembinski, P. H. (2004): «Economie solidaire: une réalité multiple», Finance $\varepsilon$ Bien Commun, 20, pp. 98-105. [http://dx.doi.org/10.3917/fbc.020.0098]. DERridA, J (1993): Spectres de Marx. Paris, Galilée.

Donati, P. (2006): Repensar la sociedad. El enfoque relacional, Madrid, Ediciones Internacionales Universitarias.

DRAPERI, J.-F. (2011): L'économie sociale et solidaire: une réponse à la crise?, Paris, Dunod.

Flahault, F. (2005): «Vers une nouvelle pensée sociale», Revue du mauss, 26, p. 377-382. [http://dx.doi.org/10.3917/rdm.026.0377].

Foucault, M. (2003): Hay que defender la sociedad, Madrid,Akal. 
GIDE, CH. (2008): Les Oeuvres de Charles Gide Vol.VI: Les institutions du progrès social, Paris, L'Harmattan.

- (2013): La coopération contre le capitalisme, Paris, Les petits matins.

Gorz, A. (2001): «LLa personne devient une entreprise». Note sur le travail de production de soi», Revue $d u$ MaUss, 18, pp.61-66. [http://dx.doi. org/10.3917/rdm.018.0061].

- (2007): "Penser l'exode de la société du travail et de la marchandise», Mouvements, 50, pp. 95-106. [http://dx.doi.org/10.3917/mouv.050.0095].

Hardin, G. (1968): "The tragedy of the commons», Science, 162, pp. 12431248. [http://dx.doi.org/10.1126/science.162.3859.1243].

Harribey, J.-M. (2010): «Éléments pour une économie politique de la soutenabilité fondée sur le recul de la marchandise», Revue française de socio-économie, 6, pp. 31-46.

JeANTEt, TH. (1999): La Economía Social Europea o la tentación de la democracia en todas las cosas, Valencia, CIRIEC-ESPAÑA.

Kovel, J. (2009): «Le capital et la domination sur la nature», Ecologie \& politique, 38, pp. 123-146. [http://dx.doi.org/10.3917/ecopo.038.0123].

LA FAGEDA (2010): «Servei de Teràpia Ocupacional», [http://www.fageda. com/servei-de-terapia-ocupacional]. Consultado el 20 de junio de 2013. Latouche, S. (2003): "L'oxymore de l'économie solidaire», Revue du MAUSS, 21, pp. 145-150. [http://dx.doi.org/10.3917/rdm.021.0145].

LAVILle, J.-L. (2001): «Vers une économie sociale et solidaire», RECMA-Revue internationale de l'economie sociale, 281, pp. 39-53.

Löwy, M. (2006): «Développement des forces productives ou subversion de l'appareil de production? Une perspective écosocialiste», Ecologie $\varepsilon$ politique, 32, pp. 53-59. [http://dx.doi.org/10.3917/ecopo.032.0053].

Marx, K. (1975): El Capital. Libro I. Vol. 1, Madrid, Siglo XXI.

Mauss, M. (2010): Essai sur le don, Paris, Quadrige/Puf.

Neamtam, N. (2003): «L'économie solidaire comme radicalisation de la démocratie», Revue du MAUSS, 21, pp. 128-134. [http://dx.doi.org/10.3917/ rdm.021.0128].

oCDE (2008): Croissance et inégalités. Distribution des revenus et pauvreté dans les pays de l'OCDE, París, OCDE.

Ostrom, E. (2000): El gobierno de los comunes. La evolución de las instituciones de acción colectiva, México, UNAM / CRI / FCE.

- (2002): «Reformulating the commons», AmbienteESociedade, 10, V, pp. 1-21. 
- (2012): «Par-delà les marchés et les États. La gouvernance polycentrique des systèmes économiques complexes", Revue de l'OFCE, 120, pp. 13-72. [http://dx.doi.org/10.3917/reof.120.0013].

Palma, C (2013): «Theodoros Karyotis portavoz de la iniciativa solidaria con Vio.Me», Diagonal Global, 19 de febrero de 2013[en línea] [https:// www.diagonalperiodico.net/global/para-recuperar-la-fabrica-nos-guiaejemplo-argentina.html]. Consultado el 21 de junio de 2013.

Polany, K. (1989): La Gran Transformación, Madrid, Ediciones La Piqueta. RICARD, X. (2011): «La société civile, laboratoire d'alternatives au productivisme?», Projet, 324 - 325, pp. 104-113. [http://dx.doi.org/10.3917/pro.324.0018].

SABOURIN, E. (2007): «L'entraide rurale, entre échange et réciprocité», Revue $d u$ MaUSS, 30, pp. 198-217. [http://dx.doi.org/10.3917/rdm.030.0198].

SANTOS, B. De Sousa (2003): La Caída de AngelusNovus: Ensayos para una nueva teoría social y una nueva práctica política, Bogotá, ILSA.

- (2006): Renovar la teoría crítica y reinventar la emancipación social. (Encuentros en Buenos Aires), Buenos Aires, Clacso.

- (2010): Descolonizar el Poder, reinventar el Saber, Montevideo, Trilce.

- (2012): De las dualidades a las ecologías, La Paz, REMTE.

Vio.Me (2013): «Vio.Me. Occupy, Resist, Produce! Solidarity to the struggle of the workers of the Vio.Me factory in Thessaloniki, Greece, for selfmanagement», [en línea] [http://www.viome.org/p/espanol.html]. Consultado el 21 de junio de 2013.

Wall Street Journal (2012): Europe's Banker Talks Tough, 24 de febrero de 2012 [en línea] [http://online.wsj.com/article/SB100014240529702039 60804577241221244896782.html]. Consultado el 12 de abril 2013.

Zamagni, S. (2012): Por una economía del bien común, Madrid, Ciudad Nueva. 